\title{
The determinants of health care utilization in rural Senegal
}

\author{
Aurelia Lepine and Alexis Le Nestour
}

\begin{abstract}
In the context of the national debate on the extension of health insurance to farming households in Senegal, information on 504 households and 18 public Primary Health Care (PHC) facilities was collected in order to analyse health care utilization in an area where people live on 1.17 USD per day and where only $6 \%$ have health insurance coverage. Despite the high level of poverty, $84 \%$ of the individuals sought treatment from a qualified health provider during their last illness. The high rate of utilization in the area is found to be attributable to the characteristics of the PHC facilities. Indeed, PHC facilities are highly accessible and offer good medical services at a low price. The low price of medical services in the sample explains why the demand for curative care is found to be price-inelastic. This latter result suggests that policies that will reduce the price of medical services to increase the health care use are not likely to be effective.
\end{abstract}




\section{Introduction}

In Senegal, households contribute directly up to $37.6 \%$ of total health financing; $89 \%$ of households' health expenditure is out-of-pocket-spending while $11 \%$ is in the form of health insurance contributions (Government of Senegal, 2009). Only 15.2\% of Senegalese have health insurance, most of whom are workers in the formal sector (Government of Senegal, 2008). A lack of health financial protection for the poorest can negatively affect their access to health care and therefore increase health inequalities. High Out-Of-Pocket medical spending (OOPs) can lead to impoverishment as many households in Senegal resort to the sale of assets and borrowing to finance their health care. As the most vulnerable households live in rural areas and depend on agriculture, the Government of Senegal voted and adopted in August 2008 the National Agrosylvo-pastoral Health Insurance Law in order to increase health care utilization and to protect every person making a living from agriculture from catastrophic health risk (Government of Senegal, 2007). The Agro-sylvo-pastoral Health Insurance project targets $60 \%$ of the total Senegalese population, which represents 7.5 million people. Because the Government of Senegal considered that people who live on agriculture do not have the financial means to afford health insurance, the Government plans to offer a subsidy of $75 \%$ of the total cost of the insurance premium to encourage farming households to join the project. Members of the project will then need to pay an annual contribution of 7 USD per capita instead of the full cost of the premium (20 USD). In return, the insured will benefit from a third-party health care reimbursement of $90 \%$ for services offered at hospital level and 70\% for services delivered at Primary Health Care (PHC) facilities. The implementation of the project will have a large effect on public health expenditure, since the project (excluding administrative costs) will cost 150 million USD per year, which represents $40 \%$ of the current health budget. Because this project is costly and the benefits that can be expected from the introduction of health insurance on health care utilization and catastrophic expenditure are unknown, the Government of Senegal has decided to implement the project on a small scale. Since the extension of health insurance to farming households is based on the belief that user fees are the main disincentive to use health services, this paper, using a multilevel modelling approach, looks at whether the demand for curative care is impeded by financial constraints in the area chosen 
to start off the project, while controlling for observed individual, household and health facilities' characteristics and unobserved heterogeneity.

More specifically, the first aim of the study is to explain the level of health care access through a deep analysis of the context. The second aim is to highlight effective policies to increase health care utilization. Although, several studies have analysed the effect of observed characteristics on the utilization of health care in Senegal (Fassin, Jeannee, Cebe, \& Reveillon, 1988; Jütting, 2004; Ndiaye et al., 2005), this study makes important contributions to the existing literature as it is the first study that simultaneously takes into account the three following points. Firstly, according to the findings of Sepehri et al. (2008), Franckel and Lalou (2009) and Lopez-Cevallos and Chi (2010), a three-level random intercept logistic model is used in order to include the effect of unobserved characteristics of community and household of the individual on the likelihood of using curative care. Secondly, the characteristics of health facilities are added in the analysis to account for the effect of the accessibility, the quality and price of medical services. Finally, indirect cost of seeking care is included through the opportunity cost of time.

The main result is that despite the high level of poverty in the survey area, the likelihood of using curative care is very high. This result is attributable to the good accessibility of PHC facilities, the high likelihood of being cured after the first medical visit and the price-inelasticity of demand that is explained by the low prices set at PHC facility level. It appears that policies that will reduce the negative effect of the time lost to seek care by workers or policies that will increase the accessibility and the quality of care will be more effective to increase health care utilization than the introduction of health insurance.

\section{Population and Data}

Senegal is a West African country with a population of approximately 12 million, of which 7 million live in rural areas. The study was conducted in Ross Béthio, Gaë and Guédé, i.e., three rural communities of the Saint-Louis region chosen to start off the health insurance project. Most of the 110,000 inhabitants of these rural communities derive their livelihoods from subsistence farming, with an annual adult equivalent ${ }^{\mathrm{i}}$ median household consumption expenditure of 848 USD, 
of which, on average, $3.9 \%$ is spent on health. The survey was carried out during May and June 2009 during the dry and warm agricultural season and targeted 505 rural households depending on agriculture for a living and belonging to a farmer organization. The data set is representative of farming households in the Saint Louis region as most of farmers in Senegal belong to a farmer organization, which appears to be a very important social structure in Senegal (DeJanvry \& Sadoulet 2004). To sample the 505 households, a two-stage stratified sampling procedure, where each household has the same probability of inclusion in the sample, was used. The definition of the household used in the survey was "a group of individuals who live and work on household plots together, prepare meals together for home consumption and pool resources in order to provide for their essential needs". This definition is based on the idea that the household is a consumption-production group and corresponds to the notion of "Njël" in Wolof or "Hirande" in Foula. An exhaustive survey has also been conducted of the 18 PHC facilities in the rural communities targeted in order to link demand-side and supply-side factors.

\section{Conceptual background}

\section{PHC facility characteristics}

In Senegal, the low quality of care and the lack of control in the health system can lead people to bypass the preliminary level (PHC facility) to consult directly with a higher-level provider (health centre or hospital). Nevertheless, the high user fees and distance associated with consulting highlevel providers explain why $72.5 \%$ of the sample went to the PHC facility the last time they visited a health facility while only $9 \%$ and $8.5 \%$ went to a health centre or to the hospital, respectively. Indeed, the average distance to the closest PHC facility is only 3.88 kilometres and $71 \%$ of the individuals live in a village where there is a PHC facility while the closest high-level provider is located, on average, 20 kilometres away from the village of the household. Of those who went to a PHC facility, 93\% went to the closest one. For this reason, it is assumed that the characteristics of the closest PHC facility will determine the likelihood of using care. The availability of a health facility, which is found to be an important determinant of health care access (Collier, Dercon, \& 
Mackinnon, 2002; Buchmueller, Jacobson, \& Wold, 2006; Ahmed \& Mahran, 2009), is measured by the average transport cost paid computed at the village level.

The price of health inputs has been studied widely in the literature because of its policy implications. Some argue that demand for treatment is inelastic to price (Heller, 1982; Akin, Griffin, Guilkey, \& Popkin, 1986), while others have shown that user fees reduce health care utilization (Yoder, 1989; Waddington \& Enyimayew, 1990; Litvack \& Bodart, 1993; Mbawu, Mwanzia, \& Liambila, 1995; Mbugua, Bloom, \& Segall, 1995; Wilkinson, Sach, \& Karim, 1997; Ngugi, 1999; Fafchamps \& Minten, 2007). Conflicting results concerning the price-elasticity of demand for health care can be due to numerous reasons, such as the context-specificity, the measure of the dependent variable, the choice of the econometric method (Bolduc, Lacroix, \& Muller, 1996), measurement error in price and quality of care indicators as well as omitted control variables. In the paper, two measures of price are used. The first is the price of inpatient care computed for the median length of stay (5 days) since the rate-making varies between health facilities; some set a fee per day, others a capitation and some offer free inpatient care. The second is a price index that is made up of the sum of three standardized variables: the price of outpatient care for adults and children and the price of inpatient care. The price of outpatient care could not be used as a proxy for price because of the low variability in the sample: most of the facilities charge 200 FCFA (0.42 USD) and 100 FCFA (0.21 USD) for adult and child outpatient care respectively. Information on the price of drugs was also collected but there was no variability in the price of the medicines available in all the facilities of the sample. Even if only a small portion of the sample (5\%) used inpatient care the last time they were sick, the financial burden of inpatient care is much larger than the one associated with outpatient care. Indeed, on average in the sample, outpatient and inpatient out-of-pocket medical spending were 0.7 USD and 46 USD respectively during the last medical visit. Patients may thus fear to need inpatient care when they go to a health provider, therefore, they can be discouraged from seeking care.

There is no consensus on how to measure quality, but subjective quality of care has to be distinguished from the objective quality of care (Palmer, Donabedian, \& Povar, 1991). The 
objective quality of care is measured by structural and process indicators such as staff medical knowledge (Das \& Hammer, 2004), medical equipment and drug availability (Mwabu, Ainsworth, \& Nyamete, 1993), while the subjective quality of care refers to the views of patients. Since there is asymmetric information between health workers and patients, it is not obvious that the observed quality of care will be correlated with the perceived quality of care. The quality of care is thus measured by the healing rate in the closest PHC facility; note that in the sample, people first refer to ineffective treatment to define a poor quality of care. Several indicators of objective quality of care are also used to test the robustness of the results.

\section{Income and time}

In the Grossman model (1972), individuals combine inputs of time and purchased medical care to produce health investments that increase utility. Grossman predicts a positive impact of income on the reduced form of the demand for medical care, which has been confirmed empirically in many developing countries (Lawson, 2004; Sepehri, et al., 2008; Habibov, 2009; Lopez-Cevallos \& Chi, 2010; Pokhrel, De Allegri, Gbangou, \& Sauerborn, 2010). Income is measured by assets owned by the household (fridge, air conditioner, fan, radio, TV, vehicle) and dwelling characteristics (source of lighting and cooking), where the weights used to construct the indicator are derived from the first dimension of a Multiple Correspondence Analysis (MCA). As a proxy for the opportunity cost of time a variable that captures whether the individual works on the household fields was interacted with the wealth quintile. It is assumed that the richest agricultural workers will face a higher opportunity cost of time of seeking treatment than the poorest farmers, the workers in the formal sector who are on the sick list and non-workers.

\section{Descriptive statistics}

During their last sickness, $82 \%$ and $84 \%$, respectively, of the total sample $(n=4469)$ and of the subsample considering their illness severe $(n=4359)$ had sought treatment. Table 1 shows that when sick individuals have decided to seek treatment, they tend to visit a qualified health worker since the demand for traditional medicine is particularly low. Table 1 also shows that the percentage of sick individuals who sought treatment during their last illness increases with wealth. 


\section{Insert Table 1}

The rate of utilization was found to vary from $80 \%$ to $87 \%$ between rural communities. Fula individuals are found to use less care than Wolof individuals $(13.5 \%$ did not use care among Wolof and $18.4 \%$ among Fula, $\mathrm{p}<0.01$ ) but this finding did not remain after controlling for location characteristics. Children under-5 are found to have a higher rate of utilization in the sample $(90 \%$ versus $82 \%$ for non-child, $\mathrm{p}<0.01)$. Women use more care than men as $85 \%$ of women and $82 \%$ of men sought treatment last illness $(\mathrm{p}<0.01)$. During last illness, 95\% of individuals having a health insurance sought treatment against $85 \%$ among the uninsured $(\mathrm{p}<0.01)$. Individuals who work in the fields of the household are found to use less care than non-agricultural workers $(81 \%$ versus $85 \%, \mathrm{p}<0.01)$. Finally, the likelihood of using care increases with the education of the head of the household since education may have an impact on the perception of the disease and on the demand for modern medicine.

The sample statistics reveal the following characteristics. People who sought medical care are very likely to recover, since among the 3911 individuals who sought treatment, 90\% were cured after the first medical visit, and among the $5 \%$ of those who had a second medical visit $(n=205), 55 \%$ were cured after this second visit. Since people who seek treatment are very likely to be cured, most people may consider seeking curative health care as effective. The average total medical expense during last illness is 16 USD and the median health expenditure is 5 USD. One may want to note that $85 \%$ of total health expense is spent on drugs. However, the price of care is found to be extremely low at PHC facilities surveyed. On average PHC facility charge 2.9 USD for inpatient care for the median length of stay (5 days), 0.43 USD for adult outpatient care and 0.24 USD for children outpatient care. When uninsured people face severe disease or injury, they have to finance their care through informal strategies as only $6 \%$ are covered by a health insurance. Table 2 shows that the channel used by households to finance their health care varies depending on the amount of out-of-pocket medical spending. The higher the health expenditure, the riskier the strategy of financing. In the sample, people are more likely to finance their health care with savings and the sale of livestock. The least efficient strategy of health financing is the sale of assets, and particularly 
the sale of non-agricultural assets, which includes equipment and vehicles. It is worth noting that the $2.6 \%$ who sold non-agricultural assets to finance health care paid on average 55 USD in outof-pocket medical spending during last illness.

\section{Insert Table 2}

\section{Method}

The binary dependent variable of health care access is measured by a visit to a qualified health worker during the individual's last illness. This allows gaining information on health-seeking behaviour for all household members and not only for those who experienced a sickness during the recall period (usually the last month), as it is commonly done in earlier surveys. The high percentage of utilization found in the sample is not associated with the way the question was asked. Indeed, we also asked the question for children in reference to the last month, and found that among the $36 \%$ who experienced an illness in that period, $80 \%$ received treatment. However, with our method a bias could occur for the persons who were sick a long time ago if those persons cannot recall which provider was visited. One may want to note that memory lapse is not very likely in an area where $27 \%$ and $36 \%$ of the adults and children, respectively, had an illness during the last month. A more plausible bias would be that people recall the last medical visit as the last time they were sick, in this case the method used would result in an over-estimation of the likelihood of using care.

Andersen (1995) identified need as a prime determinant of services' use. Perceived need is influenced by the social context and refers to how people experience their symptoms, illness and whether or not they consider their problems severe enough to visit a health provider. In the sample, among those who did not seek treatment, $18.18 \%$ did not perceive need as they declared that their disease was not severe enough to seek treatment. For those people, we do not know what their decision would have been if they did consider the disease to be severe enough to seek treatment. 
For this reason, those people were excluded from the estimates. Since they represent less than 3\% of the sample, we do not find any significant change by excluding those people from the estimates.

There are many reasons to suggest that the coefficients estimated by an ordinary model for qualitative data will be biased. First, in Senegal the head of the household has a strong decisionmaking power inside the household. In the sample, spouses declare that their husbands alone make $45 \%$ and $49 \%$ of decisions concerning their health and the health of their children, respectively. Moreover, individuals who belong to the same household share the same unobserved characteristics; thus there might be a high degree of homogeneity in health-seeking behaviour among individuals of the same household. Second, information on households and on health care suppliers was merged by the closest health facility to the village of the household. The likelihood of seeking treatment for one member is, then, assumed to correlate with the likelihood of seeking treatment for the other members of the same household and the same community. To correct for unobserved heterogeneity, a three-level logistic nested model is used. This model is a simple generalized linear mixed model with fixed effects and two random intercepts (Rabe-Hesketh \& Skrondal, 2005). To determine the level of hierarchy, a Likelihood Ratio (LR) test for a nested model was conducted.

Suppose that the probability of visiting a qualified worker for the last illness of individual $i$ in household $j$ living in the village $k\left(\mathrm{~V}_{\mathrm{ijk}}\right)$ depends on:

$\operatorname{Logit}\left\{\operatorname{Pr}\left(V_{i j k}=1 \mid X_{i j k}, \zeta_{j k}(2), \zeta_{k}^{(3)}\right)\right\}=\beta_{1}+\beta_{2} X_{2 i j k}+\ldots+\beta_{n} X_{n k}+\zeta_{j k}^{(2)}+\zeta_{k}^{(3)}$

where $\beta_{1}$ is the intercept and $\left\{\beta_{2}, \ldots, \beta_{n}\right\}$ is a vector of coefficients of the set of observed variables $X_{i j k}$ at the individual, household and village level presented in Table 3 and $\zeta_{j k^{(2)}}$ and $\zeta_{k^{(3)}}$ are randomintercept terms for level 2 (household) and level 3 (village). The random-intercept terms represent the combined effect of all omitted household-level and village-level unobserved heterogeneity that affects the health-seeking behaviour of individuals in some households and villages. 


\section{Results}

Table 4 presents marginal effects and robust standard errors $(Z)$. The intraclass correlations are $\rho($ household, village $)=0.41$ and $\rho$ (village $)=0.16$, which indicates that $41 \%$ of the total residual variance is due to the between-household residual variance and $16 \%$ is due to the between-village residual variance. So, there is an important dependence in response for individuals from the same household.

\section{Insert Table 4}

At the individual level, the likelihood of seeking treatment is influenced by the relationship to the head of the household, employment status, gender and age. The parents of the head are less likely to use care when sick after controlling for age and labour status. Age decreases the likelihood of seeking care but at a lower rate when age increases and, then, it has a positive effect for individuals older than 40 years. Finally, women have a greater likelihood of using care than men by 1.4 percentage points, which certainly reflects a stronger preference for health in women (Lele, 1986; Blumberg, 1989). The health insurance variable is not statistically significant in the sample. It is worth pointing out that insured individuals are mainly covered by a compulsory health insurance, as most of them work for the National Company of Sugar in Richard Toll. Thus, health insurance is not likely to include self-selection but is likely to be endogenous if there are differences in unobservable characteristics between those individuals and the rest of the sample.

The use of health services is also determined by household characteristics. An additional year of education of the household head increases the likelihood of individuals seeking treatment by less than one percentage point. The household economic status is a strong determinant of the likelihood of seeking care, as the likelihood of seeking treatment during last illness is greater on average by 10 percentage points for the richest. To test the robustness of the effect of income, monthly total expenditure expressed in terms of quintile is used to measure income (correlation coefficient $=0.3, \mathrm{P}<0.01)$. It is found that the richest people are also more likely to use care by 8 
percentage points than the poorest. However, one may want to note that the impact of wealth is cancelled out by labour status because of the opportunity cost of time. Indeed, one can note that the richest non-workers have a greater likelihood of seeking care by 10.5 percentage points than the poorest non-workers, whereas, the likelihood of seeking care of the richest workers is only $3.2 \%$ percentage points greater than the one of the poorest non-workers. This result is consistent with the hypothesis that the better off face a greater opportunity cost in terms of time, since when the interacted variable is omitted, the variable labour is not significant and its sign is negative. The marginal effect of the richest quintile dummy is lower than when the multiplicative variable is included, which suggests that the omission of the opportunity cost of time would result in an underestimation of the impact of wealth on the likelihood of using care. The likelihood of seeking care is computed for workers and non-workers in Table 5. It is worth noting that the net effect of labour is the same for wealth quintiles 2, 3 and 4. The labour status increases the likelihood of seeking care of the poorest workers by 4 percentage points and decreases the likelihood of seeking care of the richest workers by 7 percentage points.

\section{Insert Table 5}

Estimates were conducted separately on the samples of adult men and adult women. Results indicate that the effect of the opportunity cost of time for workers is heterogeneous in the two sub-samples, as it has a strong effect in the sample of men and no effect in the sample of women. This result may be due to the fact that women do not carry out the most important labour work, either because their work is more concerned with subsistence crops (potato) than with cash crops (rice, tomato, onion), or because they do not have a specific role in agricultural production and can be easily replaced by other household members. It may also be because they have a lower productivity than men. Thus, wealth is found to have a positive effect on the likelihood of the richest worker women seeking care $(\mathrm{ME}=0.11)$, while the richest men have a greater likelihood of seeking care by 17 percentage points, but the opportunity cost reduces the effect by 23 percentage points, suggesting that the richest worker men have a lower likelihood of seeking care by 6 
percentage points than the poorest non-worker men. Additional estimates were also conducted using other measures of the opportunity cost of time while controlling for household socioeconomic status. Firstly, the number of days of farm work of family workers expressed in terms of quartile, and secondly the land area in logarithm were used to capture the load of agricultural labour. Those variables were interacted with the labour status in order to test if workers of households who need a lot of agriculture work were less likely to seek care. The results confirm the presence of an opportunity cost of time for workers, as the two interaction terms are negative and statistically significant. Workers who belong to households that require a high load of farm work are less likely to seek care by 7.5 percentage points than the non-workers of households with a low agricultural work requirement. Results also show that an increase in one hectare of the land area owned by the household decreases the likelihood of workers seeking care by 1.3 percentage points in relation to non-workers.

At the community level, the accessibility and the quality of care of the closest PHC facility are important determinants of health care utilization. An increase in 1 USD of the average transport cost decreases the likelihood of seeking care from a qualified provider by 9 percentage points. This result is confirmed by the use of the log of the distance in kilometres, as an increase in one point in the logarithm of the distance to the closest PHC facility decreases the likelihood of seeking care by 2 percentage points. The perceived quality of care seems to be associated with a higher likelihood of seeking treatment from a qualified worker. Individuals located close to PHC facilities that have a greater healing rate were more likely to have sought care during their last illness. An increase in the healing rate of 10 percentage points increases the likelihood of seeking treatment by 4 percentage points. However, an increase in the price of care has an extremely low effect on the likelihood of seeking curative treatment. Results show that when the user fee increases by one dollar (which corresponds to a $46 \%$ increase), the likelihood of seeking treatment decreases by only 0.6 percentage point. When the price index is used, the variable is not statistically significant. This result shows that the price of medical care at the closest PHC facility has a low effect on the utilization of medical services, which is probably attributable to the low prices as on average, people 
paid 2.5 USD for inpatient care for the median length of stay i.e. 0.5 USD per day.

Other measures of the quality of care were used to test the robustness of these results. Two indicators measuring medical competence of the head nurse were used. The first one was the status of the head nurse as it is assumed that civil servants who pass the national examination will have a better medical knowledge than contract staff. We also found that in the sample, contract employees were paid four times less than civil servants, which can also have an effect on their motivation. Since head nurses have a strong decision-making influence on the facility management, their status is expected to affect the quality of care offered. This is mainly explained by the fact that decisions are decentralized and made by health committees, made up of the head nurse of the facility. The second indicator is a medical competence index that aims to evaluate the knowledge of medical protocols (Gertler, Rose, \& Glewwe, 2000; Das \& Hammer, 2004; K.L. Leonard \& Masatu, 2005; Kenneth L. Leonard, Masatu, \& Vialou, 2007). Two health-related vignettes were used: the first one was a hypothetical adult with a cough and a fever, and the second a hypothetical child patient with symptoms of diarrhoea. The competence index is positively correlated with the status of the head nurse, which confirms the assumption that civil servants have better medical competence (correlation coefficient $=0.29, \mathrm{p}<0.01)$. The second type of indicator used is the number of essential drugs available in the PHC facility. The list of essential drugs that should be available at each level of the referral system in Senegal was obtained from the "Réseau Médicaments et Développement".

Using all the possible combinations of price and quality variables in several estimates the medical competence of the head nurse and his/her status were always significant in explaining health care utilization. Results indicate that when the head nurse in the closest PHC facility is a civil servant, the likelihood of seeking curative care increases by 8 percentage points and that an increase in one standard deviation in the medical competence index increases the likelihood of seeking treatment by 10 percentage points. However, the number of drugs available in the facility was never significant in explaining health care utilization.

Insert Table 6 
As shown in Table 6, a possible reason for this finding is that greater drug availability is not associated with a higher likelihood of being healed and might not capture the quality of care perceived by patients. This could be explained by the fact that high drug availability may be associated with a greater percentage of out of date medicines. As the medicines inventory conducted at PHC facilities focused on one essential drug per category of disease (the most prescribed essential drug), it is also possible that other essential drugs that are relevant in the treatment of a specific illness were available at the facility.

Finally, the price of care was also measured by a price index based on the mean of three standardized price variables (outpatient care for adults, outpatient care for children and inpatient care). An interesting finding is that the price indicators were never statistically significant when other variables of quality and availability were used.

We estimated the model using the three-level random intercept logistic model for different subgroups. Price elasticities were computed with the mid-point method by setting all covariates at mean. Table 7 shows that the overall price-elasticity of inpatient care is close to 0 in the total sample, thus the demand for health is found to be highly inelastic for the different groups although, the price-elasticity is greater in the sub-groups of poor and women. Similar conclusion was obtained from the analysis of the elasticity of transport price as an increase in $100 \%$ in the average transport cost decreases the likelihood of using care by $9.4 \%$ in the total sample and by $15.7 \%$ for the $50 \%$ poorest.

\section{Insert Table 7}

Price elasticities were also computed assuming that the agro-sylvo-pastoral project is implemented and that individuals benefit from a decrease in price by $70 \%$ for inpatient care sought at PHC facilities. Results indicate that a $70 \%$ decrease in price will increase total health care utilization by only $1.34 \%$ in total sample, utilization increasing by $0.4 \%$ and $1.74 \%$ for the richest and the poorest 
sub-groups, respectively. Assuming that price-elasticity may vary depending on the price of inpatient care set by each PHC facility, the price-elasticity curve was simulated from the random intercept model.

\section{Insert Figure 1}

Figure 1 shows that price-elasticity increases with the price of inpatient care, suggesting that the price-inelasticity found in the total sample may be attributable to the average low price of inpatient care. Price-elasticity of demand may thus be greater for the patients who went to a high-level since the price of inpatient care set by those facilities is more than four times greater than the average price of inpatient at PHC facilities. It is worth noting that the demand for health is perfectly priceinelastic when the price of inpatient care is less than 2 USD, which suggests that PHC facilities offering free inpatient care could increase their financial resources by charging 2 USD without affecting the rate of health care utilization.

Income elasticity was also computed by using monthly expenditure in adult equivalent (USD) as a proxy for income. Table 8 shows that an increase in monthly household income in adult equivalent by $100 \%$ will only increase health care utilization by $2.5 \%$ for workers and $2.9 \%$ for non-workers. Thus, although the demand for health care is found to be responsive to household income, an increase in real income will have a low effect on the demand for care as health is found to be a necessity good.

Insert Table 8

\section{Discussion and conclusion}

The determinants of health-seeking behaviour in rural Senegal were analysed before the introduction of a health insurance scheme for farmers. It was found that about $84 \%$ of people, who had a health need, sought curative treatment, which shows that health care access is high in 
this rural area of Senegal. The high utilization rate of curative care is found to be explained in the sample by:

a. A high likelihood to be cured if treatment is received;

b. A good accessibility of PHC facilities;

c. The low level of prices set at PHC facilities resulting in the price-inelasticity of the demand;

d. The low demand for traditional medicine.

The main result suggests that the introduction of health insurance to farmers will have a low effect on health care utilization because the demand for health care is found to be price-inelastic. Moreover, the introduction of subsidized health insurance will be costly so they might be more effective policies to implement to increase health care utilization. An increase in household wealth through a cash transfer program for instance is also likely to be ineffective because, first, health is found to be a sticky good and, second, the effect of wealth on utilization will be almost nil for workers because of the effect of the opportunity cost of their time. However, an improvement in the accessibility of health facilities through better road quality and better means of transport will have a positive effect on health care utilization, ceteris paribus. Those policies will certainly reduce the negative effect of the opportunity cost of time by reducing the travel time to the facility. Policies that will reduce the opportunity cost of time could also be very effective in increasing health care utilization. For instance, one might consider opening the health facility early in the morning or late in the afternoon to allow workers to seek care without losing a day of labour. One might also think about the pertinence of developing the use of mobile phones for medical advice, which might encourage those who are severely ill to seek care. Quality of care also emerged as an important determinant of health care utilization in our sample. Results suggest that hiring civil servants in rural areas is effective because they have better medical competence and they are more motivated than staff on contract. Indeed, after controlling for medical competence, the likelihood of being healed was still found to be greater in facilities where the head nurse was a civil servant. Finally, it is surprising to find that the parents of the household head are less likely to access care because in Senegal the "Plan Sésame" policy offers free care to individuals who are more than 60 years old. 
Regressions were run for the sub-samples of elderly and it was interesting to note than none of the explanatory variables were statistically significant, so perhaps there are cultural factors that prevent the elderly from seeking care in Senegal.

Finally, it is worth noting that the non-significance of price in the analysis should not be interpreted to mean that there is no financial problem in health care access, as in the survey area this could just reflect the low prices set at PHC facilities. Even if the patient has sought treatment for their most recent illness, the time waited before seeking treatment is not known. Greater prices could result in an increase in the waiting time before seeking treatment, which could result in negative externalities (direct and indirect costs paid by infected individuals) since the disease could spread to other household members. Moreover, although a large proportion of people are willing to seek treatment, the sacrifices undertaken by the household to be treated are unknown. Severe illness probably affects the composition of expenditure of the household by depriving it of resources that could have been spent on other goods and services (Wagstaff, 2008). A high rate of health care access can also be correlated with an impoverishment of households, as the obligation to pay a relatively large amount of money for treatment for a disease can lead households to poverty by forcing them to sell assets or borrow money. The finding that health is a sticky good reinforces the idea that health insurance is needed to reduce the likelihood of catastrophic expenditure. 
Table 1: Percentage of visits during last illness by type of provider and wealth quintile

\begin{tabular}{llllllll}
\hline $\begin{array}{l}\text { Wealth } \\
\text { quintile }\end{array}$ & $\begin{array}{l}\text { Qualified } \\
\text { worker }\end{array}$ & $\begin{array}{l}\text { Community } \\
\text { staff }\end{array}$ & Pharmacist & $\begin{array}{l}\text { Traditional } \\
\text { Healer }\end{array}$ & $\begin{array}{l}\text { Self- } \\
\text { treatment }\end{array}$ & No care & $\begin{array}{l}\text { Visit } \\
\text { someone }\end{array}$ \\
\hline Poorest & 76.38 & 1.38 & 0.30 & 2.46 & 12.99 & 6.00 & 80.52 \\
2 & 81.11 & 0.69 & 0.23 & 2.53 & 10.37 & 5.07 & 84.56 \\
3 & 82.11 & 2.57 & 0.27 & 2.66 & 5.58 & 6.64 & 87.61 \\
4 & 87.73 & 0.00 & 0.17 & 0.5 & 6.72 & 4.37 & 88.4 \\
Richest & 85.37 & 0.12 & 0.93 & 1.86 & 6.27 & 4.99 & 88.28 \\
\hline Total & 81.99 & 1.12 & 0.38 & 2.15 & 8.48 & 5.57 & 85.64 \\
\hline
\end{tabular}


Table 2: Out-of-pocket spending during last sickness according to the main financing strategy

\begin{tabular}{lll}
\hline $\begin{array}{l}\text { Main financing strategy used to pay for out-of- } \\
\text { pocket medical spending during last illness }\end{array}$ & $\begin{array}{l}\text { Percentage of the } \\
\text { sample using this } \\
\text { strategy }\end{array}$ & $\begin{array}{l}\text { Average Out-of-Pocket } \\
\text { last medical contact } \\
\text { (USD) }\end{array}$ \\
\hline Health insurance & 3.5 & 11 \\
Savings & 52 & 13 \\
Sales of agricultural output & 26.5 & 15 \\
Loan from relatives & 5.9 & 25 \\
Sale of agricultural asset (livestock) & 0.4 & 25 \\
Sale of non-agricultural asset (equipment, vehicle) & 2.6 & 55 \\
\hline
\end{tabular}


Table 3: Description of the dependent and independent variables in the total sample

\begin{tabular}{|c|c|c|c|c|c|c|}
\hline Variables & Description & Obs. & Mean & SD & Min & Max \\
\hline \multicolumn{7}{|l|}{ Individual level } \\
\hline Independent & Individual $i$ sought treatment when last disease & & & & & \\
\hline variable & was perceived as severe & 4359 & 0.84 & 0.37 & 0 & 1 \\
\hline Household Head & $i$ is the Household Head $(\mathrm{HH})$ & 4512 & 0.11 & 0.31 & 0 & 1 \\
\hline Wife & $i$ is the wife of the $\mathrm{HH}$ & 4512 & 0.12 & 0.32 & 0 & 1 \\
\hline Child & $i$ is the child of the $\mathrm{HH}$ & 4512 & 0.47 & 0.5 & 0 & 1 \\
\hline Parent & $i$ is a parent of the $\mathrm{HH}$ & 4512 & 0.03 & 0.16 & 0 & 1 \\
\hline Other relative & $i$ is another member of the $\mathrm{HH}$ & 4512 & 0.27 & 0.44 & 0 & 1 \\
\hline Age & Age of $i$ & 4512 & 23 & 19 & 0 & 98 \\
\hline Age-squared & Age-squared of $i$ & 4512 & 877 & 1300 & 0 & 9604 \\
\hline Gender & $i$ is a female & 4512 & 0.51 & 0.45 & 0 & 1 \\
\hline Insurance & $i$ has health insurance & 4326 & 0.06 & 0.24 & 0 & 1 \\
\hline Education & Years of education of $i$ & 4454 & 2.31 & 3.5 & 0 & 14 \\
\hline Labour & $i$ works on the fields of the household $(b)$ & 4484 & 0.28 & 0.45 & 0 & 1 \\
\hline Labour*wealth1 & $i$ is an agricultural worker and belong to Q1 & 4483 & 0.06 & 0.23 & 0 & 1 \\
\hline Labour*wealth2 & $i$ is an agricultural worker and belong to Q2 & 4483 & 0.06 & 0.24 & 0 & 1 \\
\hline Labour*wealth3 & $i$ is an agricultural worker and belong to Q3 & 4483 & 0.05 & 0.23 & 0 & 1 \\
\hline Labour*wealth4 & $i$ is an agricultural worker and belong to Q4 & 4483 & 0.06 & 0.23 & 0 & 1 \\
\hline Labour*wealth5 & $i$ is an agricultural worker and belong to Q5 & 4483 & 0.05 & 0.22 & 0 & 1 \\
\hline \multicolumn{7}{|l|}{ Household level } \\
\hline Wealth quintile 1 & $b$ is in the wealth quintile 1 & 504 & 0.23 & 0.41 & 0 & 1 \\
\hline Wealth quintile 2 & $b$ is in the wealth quintile 2 & 504 & 0.22 & 0.41 & 0 & 1 \\
\hline Wealth quintile 3 & $b$ is in the wealth quintile 3 & 504 & 0.20 & 0.4 & 0 & 1 \\
\hline Wealth quintile 4 & $b$ is in the wealth quintile 4 & 504 & 0.19 & 0.39 & 0 & 1 \\
\hline Wealth quintile 5 & $b$ is in the wealth quintile 5 & 504 & 0.16 & 0.37 & 0 & 1 \\
\hline Age of $\mathrm{HH}$ & Age of $\mathrm{HH}$ & 504 & 51 & 12.78 & 18 & 89 \\
\hline Education $\mathrm{HH}$ & Years of education of the $\mathrm{HH}$ & 500 & 2.29 & 3.82 & 0 & 14 \\
\hline Household size & Size of the household & 504 & 8.93 & 3.84 & 1 & 19 \\
\hline \multicolumn{7}{|l|}{ Village level } \\
\hline Head nurse status & Head nurse is civil servant & 39 & 0.9 & 0.31 & 0 & 1 \\
\hline Drug availability & Number of essential drug available & 39 & 19 & 3.4 & 12 & 26 \\
\hline Competence index & Medical knowledge of the nurse & 32 & 0.32 & 0.28 & -0.3 & 1.13 \\
\hline Healing rate & Healing rate in the closest PHC facility & 39 & 89.7 & 5.33 & 78.5 & 97 \\
\hline \multicolumn{7}{|l|}{ Price of inpatient } \\
\hline care & Price of inpatient care (USD) & 39 & 2.18 & 3.41 & 0 & 10.5 \\
\hline Price index & Mean of standardized price variables & 39 & -0.05 & 0.78 & -0.4 & 2.9 \\
\hline Average transport & Average transport cost to the closest PHC facility & & & & & \\
\hline $\begin{array}{l}\text { cost } \\
\text { Log(distance) }\end{array}$ & (USD) & 39 & 0.36 & 0.32 & 0 & 1.36 \\
\hline $\log ($ distance $)$ & Logarithm of the distance to closest PHC in $\mathrm{km}$ & 39 & 0.6 & 0.9 & 0 & 2.8 \\
\hline
\end{tabular}


Table 4: Determinants of the use of curative care from a qualified worker during last illness

\begin{tabular}{|c|c|c|c|c|}
\hline & (1) & & (2) & \\
\hline & $\mathrm{ME}$ & SE & ME & SE \\
\hline Wife (ref: $\mathrm{HH}$ ) & 0.019 & 0.017 & 0.019 & 0.017 \\
\hline Child & -0.023 & 0.018 & -0.023 & 0.018 \\
\hline Parents & $-0.043^{*}$ & 0.027 & $-0.043^{*}$ & 0.026 \\
\hline Other & 0.000 & 0.019 & 0.000 & 0.019 \\
\hline Age & $-0.004 * * *$ & 0.001 & $-0.004 * * *$ & 0.001 \\
\hline Age squared & $0.00005^{* * *}$ & 0.000 & $0.00005^{* * *}$ & 0.000 \\
\hline Medical Insurance & 0.044 & 0.032 & 0.044 & 0.032 \\
\hline Gender (ref: Male) & $0.014^{*}$ & 0.008 & $0.014^{*}$ & 0.008 \\
\hline Education & 0.002 & 0.001 & 0.002 & 0.001 \\
\hline Labour & $0.041 * *$ & 0.020 & $0.041^{* *}$ & 0.020 \\
\hline Wealth quintile 2 & $0.042^{* *}$ & 0.020 & $0.042^{* *}$ & 0.020 \\
\hline Wealth quintile 3 & $0.055^{* *}$ & 0.022 & $0.054^{* *}$ & 0.022 \\
\hline Wealth quintile 4 & $0.066^{* * *}$ & 0.025 & $0.066^{* * *}$ & 0.024 \\
\hline Wealth quintile 5 & $0.105^{* * *}$ & 0.029 & $0.104 * * *$ & 0.029 \\
\hline Labour*wealth2 & $-0.053 * *$ & 0.025 & $-0.052 * *$ & 0.025 \\
\hline Labour*wealth3 & $-0.049 *$ & 0.026 & $-0.048^{*}$ & 0.026 \\
\hline Labour*wealth4 & $-0.053 * *$ & 0.027 & $-0.053 * *$ & 0.027 \\
\hline Labour*wealth5 & $-0.114 * * *$ & 0.031 & $-0.113^{* * *}$ & 0.031 \\
\hline Age of $\mathrm{HH}$ & 0.000 & 0.001 & 0.000 & 0.001 \\
\hline Education of $\mathrm{HH}$ & $0.004 * *$ & 0.002 & $0.004 * *$ & 0.002 \\
\hline Household size & 0.000 & 0.002 & 0.000 & 0.002 \\
\hline Average transport cost & $-0.107 * * *$ & 0.037 & $-0.099 * * *$ & 0.037 \\
\hline Healing rate (10\% point) & $0.04 *$ & 0.022 & $0.04 *$ & 0.022 \\
\hline Price of inpatient care (1 USD) & $-0.006^{*}$ & 0.003 & & \\
\hline Price index & & & -0.017 & 0.015 \\
\hline$\overline{\left.\zeta^{2}\right)}$ & 1.36 & 0.11 & 1.36 & 0.11 \\
\hline$\zeta^{(3)}$ & 0.88 & 0.17 & 0.89 & 0.19 \\
\hline Obs. Level 1 & 4157 & & 4157 & \\
\hline Obs. Level 2 & 500 & & 500 & \\
\hline Obs. Level 3 & 39 & & 39 & \\
\hline Log Likelihood & -1397 & & -1398 & \\
\hline
\end{tabular}

(1) LR test: $\mathrm{Chi}^{2}(2)=334, \mathrm{P}=0.000$ and (2) LR test: $\mathrm{Chi}^{2}(2)=339, \mathrm{P}=0.000$ 
Table 5: Likelihood of seeking care depending on wealth quintile and labour status (ME)

\begin{tabular}{llll}
\hline $\begin{array}{l}\text { Wealth } \\
\text { quintile }\end{array}$ & Non-Workers & Workers & $\begin{array}{l}\text { Net effect of } \\
\text { labour status }\end{array}$ \\
\hline 1 (poorest) & 0 & +4 & +4 \\
2 & +4 & +3 & -1 \\
3 & +5 & +4 & -1 \\
4 & +7 & +6 & -1 \\
5 (richest) & +10 & +3 & -7 \\
\hline
\end{tabular}


Table 6: Impact of observed quality of care indicators on the likelihood of being healed (Logit model $)^{\text {ii }}$

\begin{tabular}{|c|c|c|c|}
\hline & (1) & $(2)$ & (3) \\
\hline Head nurse status & $0.04^{* *}$ & & \\
\hline Competence index & & $0.04 *$ & \\
\hline Number of available medicines & & & 0.001 \\
\hline Pseudo R-squared & 0.05 & 0.05 & 0.05 \\
\hline Observations & 3168 & 2644 & 3168 \\
\hline
\end{tabular}


Table 7. Price-elasticity of demand for inpatient care and transport cost

\begin{tabular}{lll}
\hline & Price-elasticity of inpatient care & Price-elasticity of transport cost \\
\hline Total sample & 0.024 & 0.094 \\
& & \\
Women & 0.026 & 0.106 \\
Men & 0.010 & 0.088 \\
& & \\
Age $<12$ & 0.015 & 0.066 \\
Age $\geq 12$ & 0.017 & 0.103 \\
& & \\
$50 \%$ richest & 0.011 & 0.035 \\
$50 \%$ poorest & 0.030 & 0.157 \\
\hline
\end{tabular}


Table 8. Income-elasticity of health care utilization for workers and non-workers

\begin{tabular}{|c|c|c|c|}
\hline Groups & $\begin{array}{l}\text { Workers income- } \\
\text { elasticity }\end{array}$ & $\begin{array}{l}\text { Non-workers } \\
\text { elasticity }\end{array}$ & income- \\
\hline Total sample & 0.025 & 0.029 & \\
\hline Women & 0.035 & 0.034 & \\
\hline Men & 0.017 & 0.031 & \\
\hline $50 \%$ richest & 0.012 & 0.009 & \\
\hline $50 \%$ poorest & 0.069 & 0.071 & \\
\hline
\end{tabular}


Figure 1: Health care use depending on the price of inpatient care

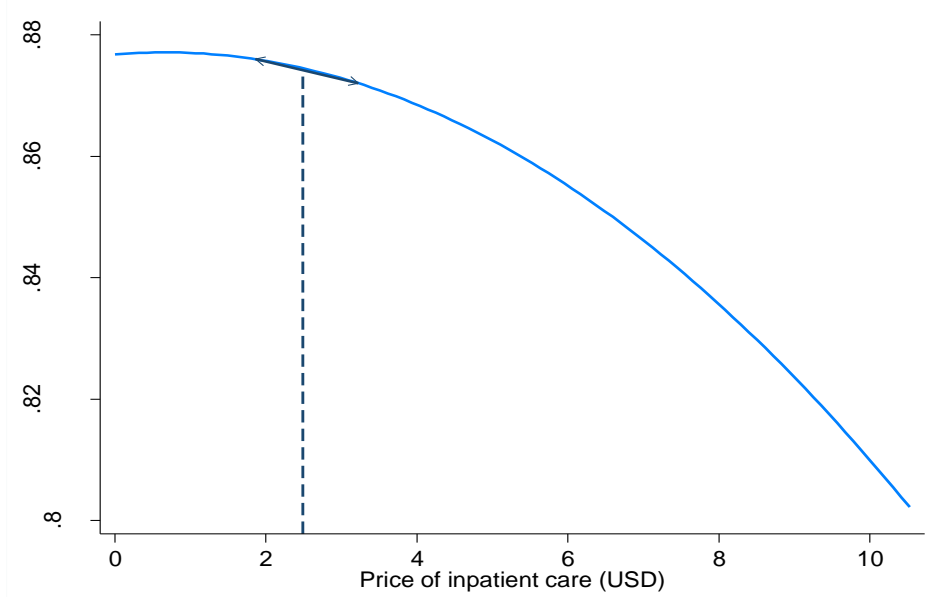




\section{References}

Ahmed, H. M. M., \& Mahran, H. A. (2009). Determinants of Demand for Delivery Services in Sudan: An Empirical Investigation with Reference to Khartoum State. African Development Review, $21(3)$, 514-540.

Akin, J. S., Griffin, C. C., Guilkey, D. K., \& Popkin, B. M. (1986). The demand for adult outpatient services in the Bicol region of the Philippines. Social Science \& Medicine, 22(3), 321-328.

Andersen, R. M. (1995). Revisiting the behavioral model and access to medical care: does it matter? Journal of health and social behavior, 36(1),1-10.

Blumberg, R. L. (1989). Making the Case for the Gender Variable. Washington, DC: AID.

Bolduc, D., Lacroix, G., \& Muller, C. (1996). The choice of medical providers in rural Bénin: A comparison of discrete choice models. Journal of Health Economics, 15(4), 477-498.

Buchmueller, T. C., Jacobson, M., \& Wold, C. (2006). How far to the hospital?: The effect of hospital closures on access to care. Journal of Health Economics, 25(4), 740-761.

Collier, P., Dercon, S., \& Mackinnon, J. (2002). Density versus quality in health care provision: using household data to make budgetary choices in Ethiopia. The Centre for the Study of African Economies Working Paper Series, 176.

Das, J., \& Hammer, J. (2004). Which doctor? Combining vignettes and item response to measure doctor quality. World Bank Policy Research Working Paper No. 3301.

Deaton, A., \& Zaidi, S. (1999). Guidelines for Constructing Consumption Aggregates for Welfare Analysis: Princeton, Woodrow Wilson School - Development Studies.

DeJanvry, A., \& Sadoulet, E. (2004). Organisations Paysannes et Développement Rural Au Sénégal. The World Bank.

Fafchamps, M., \& Minten, B. (2007). Public Service Provision, User Fees and Political Turmoil. Journal of African Economies, 16(3), 485-518.

Fassin, D., Jeannee, E., Cebe, D., \& Reveillon, M. (1988). Who Consults and Where? Sociocultural Differentiation in Access to Health Care in Urban Africa. International Journal of Epidemiology, 17(4), 858-864. 
Franckel, A., \& Lalou, R. (2009). Health-seeking behaviour for childhood malaria: household dynamics in rural Senegal. Journal of biosocial science, 41(1), 1-19.

Gertler, P. J., Rose, E., \& Glewwe, P. (2000). Module for Chapter 8. In M. Grosh \& P. Glewwe (Eds.), Health in Designing Household survey questionnaires for developing countries: lessons from 15 years of the living standards measurement study (Vol. Volume three): The World Bank.

Government of Senegal. (2007). Plan de développement du projet de mise en place d'un régime de protection sociale pour les personnes exercant les métiers de l'agriculture.

Government of Senegal. (2008). Stratégie nationale d'extension de la couverture du risque maladie des Sénégalais.

Government of Senegal. (2009). Compte nationaux de la santé. 2005.

Grossman, M. (1972). On the Concept of Health Capital and the Demand for Health. Journal of Political Economy, 80(2), 223-255.

Habibov, N. (2009). What determines healthcare utilization and related out-of-pocket expenditures in Tajikistan? Lessons from a national survey. International Journal of Public Health, 54(4), $260-266$.

Heller, P. S. (1982). A model of the demand for medical and health services in Peninsular Malaysia. Social Science \& Medicine, 16(3), 267-284.

Jütting, J. P. (2004). Do Community-based Health Insurance Schemes Improve Poor People's Access to Health Care? Evidence From Rural Senegal. World Development, 32(2), 273-288. Lawson, D. (2004). Determinants of Health Seeking Behaviour in Uganda-Is it Just Income and User Fees That Are Important? Institute for Development Policy and Management.

Lele, U. (1986). Women and structural transformation. Economic Development and Cultural Change, 34(2), 195-221.

Leonard, K. L., \& Masatu, M. C. (2005). The use of direct clinician observation and vignettes for health services quality evaluation in developing countries. Social Science \& Medicine, 61(9), 1944-1951. 
Leonard, K. L., Masatu, M. C., \& Vialou, A. (2007). Getting Doctors to Do Their Best: The Roles of Ability and Motivation in Health Care Quality. The Journal of Human Resources, 42(3), 682700.

Litvack, J., \& Bodart, C. (1993). User fees plus quality equals improved access to health care: results of a field experiment in Cameroon. Social Science \& Medicine, 37(3), 369 - 383.

Lopez-Cevallos, D. F., \& Chi, C. (2010). Health care utilization in Ecuador: a multilevel analysis of socio-economic determinants and inequality issues. Health Policy and Planning, 25(3), 209218.

Mbawu, G., Mwanzia, J., \& Liambila, W. (1995). User charges in government health facilities in Kenya: effect on attendance and revenue. Health Policy and Planning, 10(2), 164-170.

Mbugua, J. K., Bloom, G. H., \& Segall, M. M. (1995). Impact of user charges on vulnerable groups: The case of Kibwezi in rural Kenya. Social Science \& Medicine, 41(6), 829-835.

Mwabu, G., Ainsworth, M., \& Nyamete, A. (1993). Quality of Medical Care and Choice of Medical Treatment in Kenya: An Empirical Analysis. The Journal of Human Resources, 28(4), 838-862.

Ndiaye, P., Dia, T., Diedgiou, A., Diediou, A., Dieye, E. H., \& Dione, D. A. (2005). Socio-cultural determinants of the lateness of the first prenatal consultation in a health district in Senegal. Santé publique, 17(4), 531-538.

Ngugi, R. (1999). Health-seeking Behaviour in the Reform Process for Rural Households: The Case Study of Mwea Division, Kirinyaga District, Kenya. African Economic Research Consortium.

Palmer, R., Donabedian, A., \& Povar, G. (1991). Striving for quality in health care: an inquiry into policy and practise. Health administration press.

Pokhrel, S., De Allegri, M., Gbangou, A., \& Sauerborn, R. (2010). Illness reporting and demand for medical care in rural Burkina Faso. Social Science \& Medicine, 70(11), 1693-1700.

Rabe-Hesketh , S., \& Skrondal, A. (2005). Multilevel and Longitudinal Modeling Using Stata. Stata Press.

Sepehri, A., Moshiri, S., Simpson, W., \& Sarma, S. (2008). Taking account of context: how important are household characteristics in explaining adult health-seeking behaviour? The case of Vietnam. Health Policy and Planning, 23(6), 397-407. 
Waddington, C., \& Enyimayew, K. A. (1990). A price to pay, part 2: The impact of user charges in the Volta region of Ghana. The International Journal of Health Planning and Management, 5(4), 287-312.

Wagstaff, A. (2008). Measuring Financial Protection in Health: World Bank Policy Research Working Paper Series.

Wilkinson, D., Sach, M. E., \& Karim, S. S. A. (1997). Examination of attendance patterns before and after introduction of south africa's policy of free health care for children aged under 6 years and pregnant women. BMJ, 314(7085), 940-941.

Yoder, R. A. (1989). Are people willing and able to pay for health services? Social Science \& Medicine, $29(1), 35-42$.

\footnotetext{
i As households differ in size and demographic composition, equivalence scales are used to make comparable consumption indicators. The cost of a child relative to that of an adult was fixed at 0.3 while the economies of scale was set at 0.8 following recommendations from Deaton and Zaidi (1999).

ii Control variables include the gender, age, education of the patient, the age and education of the household head as well as household wealth, whether or not the patient received a prescription for $\mathrm{X}$-ray, lab test, drug and whether he/she had inpatient care.
} 